\title{
Metastatic Laryngeal Carcinoma
}

National Cancer Institute

\section{Source}

National Cancer Institute. Metastatic Laryngeal Carcinoma. NCI Thesaurus. Code

C156085.

A carcinoma that arises from the larynx and has metastasized to another anatomic site. 